\title{
Fundamental Theology at the Crossroads: Challenges and Alternatives After a Long Maturation
}

\section{LLUIS OVIEDO}

Pontifical University Antonianum, Roma loviedo@antonianum.eu

ORCID: 0000-0001-8189-3311

\begin{abstract}
Fundamental Theology (FT) has undergone a slow evolution, as many other theological disciplines, since its inception in the aftermath of the Second Vatican Council. The lapsed time invites us to reflect about the current situation in this field and to what extent that theological section is pursuing its main objectives, especially for its teaching at different levels. After examining several issues that could have influenced that development, some suggestions for advancing the field and its teaching will also be given. Indeed, both the internal and external contexts have changed quite a lot in the last 60 years, and this probably will influence a treaty that should be more contextually sensitive and very bound to developments in religious education.
\end{abstract}

Keywords: Apologetics; Revelation; Faith; Credibility; Secularization; Science.

After several decades practitioners could claim that Fundamental Theology (FT), as a theological sub-discipline, has been fixed, in an almost canonical way. This is reflected in most courses' curricula and in many published manuals. A distinctive configuration with its specific contents, distinct from other theological disciplines, can be identified. That fixa- 
tion could contrast with the expected evolution required to keep alive and thriving an academic discipline and its teaching. Indeed, the suggested development is by no ways easy or peaceful; a universal consensus among professors devoted to FT about such possible evolution is not in sight. The attempts at reforming are just timid and rather discrete. They should still interest many colleagues open to explore those different horizons. New challenges emerge and strong pressures are coming both from the cultural context and still more from the most recent Catholic Magisterium. Both are presenting indications that clearly affect the way we understand FT and its program.

In the new conditions hitherto perceived, it would be advisable to review what FT has meant, its role in contemporary theological programs as a whole, before moving on to an analysis that considers the pending tasks, and the most urgently required extensions after noticing new issues and challenges. The aim is to design a program for FT that assumes the stimuli that Catholic Magisterium has recently proposed, as well as the questions arising in the cultural environment in which faith is proclaimed and lived, a context very different from that which traditional theology knew, and even, the reflection born during the last Vatican Council, from which more than half a century has passed. The difficulties are more apparent in the educational context, where often students feel a mismatch between what is being taught, and the real problems they perceive for religion, faith and Church.

In my view, that revision task should be framed within a program that conceives theology, and still more the Fundamental, as a dynamic project, and not just as a repetition of already acquired ideas, or just to provide comments on canonical texts from the past. Surely there is much more that theology can do in the dialogue between faith and reason, and in updating a salvation message that must be understood in changing cultures and transmitted as something credible. Theological treatises are surely also subject to the trends of cultural evolution and the need to adapt to different and often difficult contexts, a move that demands much more flexibility and openness. 
Theology in general, and Fundamental theology in particular, is struggling today before a serious dilemma: whether to become a private discourse within the Church, aimed at the formation of ministers and pastoral agents; or whether to assume the challenge to become a public discourse, connected with other academic disciplines and with the cultural environment, subject to scrutiny and discussion not only internal, but also external, and attentive to the features and trials of our own time, and our own cultures. Obviously, the first option implies somehow a withdrawal and a disengagement, and surely moves away from the ideals proposed by the last Popes, urging us to engage in the dialogue between faith and reason, between Gospel and culture. However, the second option entails many risks and a huge effort. It places theology in a more relational and less self-referential style, something quite hard and uncomfortable, and requiring us to pay attention, study of, and exchange with foreign knowledge or sources relevant for theology's own development.

\section{Symptoms of Crisis}

\subsection{Concerning Revelation and its theology}

Fundamental theology arises from a need to establish the basic points of faith, or in other words, from a search for essentiality, or to focus faith on the essential, to distinguish it from the secondary or accessory, and to build both epistemological and content foundations that render possible or legitimate theology as an academic discipline. This program was more than justified, either in response to the attacks-in modern times towards Christian faith and Churches; or after the broad project of theological refoundation once previous models did not work any longer. The former foundations were, as a general rule, based on traditional medieval scholasticism and classical philosophy providing its rational scaffolding for Christian doctrines.

In retrospect, I have the impression that the theological project that emerges from the attempt at a re-founding of theology after the Second Vatican Council mainly focused on Revelation and emphasized the 'his- 
tory of salvation' as the central notion that grounded Revelation and provided its best framework. In that way, theology could avoid the need to resort to rational or philosophical foundations alien to that history and to everything related to Christian sources. As most students know, such a vision also involved a Christological concentration and a recognized privilege to Bible and its study, which became in those years the stronghold and centre of theological studies. In fact, if Revelation acquired such excellence, its accurate and finest analysis should assume a first-rate role. The almost absolutization of Revelation led, probably as an unwanted effect, to a devaluation and neglect of other 'theological loci', or other sources of inspiration, and, above all, to the almost complete abandonment of the program built around traditional apologetics, which lost its meaning within the framework and curriculum of the new FT with its refoundation program.

My generation grew up in that environment and in the idea that faith made sense in its reference to Revelation, especially biblical, and that it ceased to make sense outside that framework; everything else became secondary or lost interest. The main theological handbook for Catholic theology students in those years was the Mysterium Salutis, a title that clearly unveils a program: to develop systematic theology on the strong foundation of salvation history. A situation was reached in which the centrality attributed to Revelation turned out everything else as almost insignificant for theological analysis. This tendency could explain somehow why pressing issues like social secularization were lost or wrongly focused from that theology: since there were no Biblical references about such a phenomenon, as it was unheard of, many deduced that religious indifference was not worth it to pay attention. Indeed, there was no place in a revelation-based theology for that topic, because from a biblical perspective it made little sense that many people could become so insensitive to religious faith. Something like that happened with scientific development and with cultural tendencies that surprised everybody with their novelty. Many issues arising from scientific progress were left unanswered, among other reasons because they lacked any connection to the biblical canon or its central themes. 
Things are worsening in the last number of years and some recent developments have raised much harder challenges for a Revelation-centred theology. Two among them need to be addressed: the crisis that biblical studies entail for a theology based on salvific history; and very authoritative doubts about the foundational capacity that revelation can provide for moral theology. In the first case, the story is well known, but few dare to draw the consequences. Students attending these years Bible courses at Biblical High institutions, learn how many professors take for granted that a good deal of Biblical history prior to the Exile in Babylon would be a literary creation composed by the circles of Jewish sages exiled and pressed after the need to safeguard Israel's identity in threatening circumstances. This is not the first time that we heard about such critical voices, becoming in the Biblical Studies a standard. In fact, there is no archaeological evidence, nor documentary, nor of any kind that can confirm the stories of the Judges and the first Kings, and even less those covering previous stages in Israel's long history. If this is the case, then theology that was built on the centrality of salvation history losses its sense, especially the foundational idea that pointed to coherence and complementarity between the historical event and the texts that interpreted it, or that projected meaning on them. In fact, it is rather the text that creates the event, which has then a secondary role.

Obviously, we have still all the post-exilic history, much more reliable and better documented, and even more so the New Testament, but the consequences born from the analysis of our biblical colleagues cannot leave untouched at least two theological generations that grew from a different view and with a much more ambitious concept of Revelation. Now, the impression is that it is the performative force perceived in inspired texts, whatever their historical background, that renders them extraordinary and effective documents in guiding a people's conscience and a history that in any case knew a very important evolution in those centuries, and determined the birth and development of Christian faith. To make matters worse, the recent publication of essays such as that from the biblical scholar John Barton, A History of the Bible (Barton 2019) brings out the rather troublesome and often inconsistent character of the biblical 
text, even when considering the Pauline canon. This approach discourages a simple and foundational use of biblical revelation, which rather requires a good hermeneutical intervention, or, in other words, a foundation itself to render it reasonable and understandable in its wide variety and plural stance. It is almost ironic that theology recognised biblical studies as having so much authority. It feels instead disproved by those same biblical scholars and all this process urges a rethinking of the categories that founded that renewal program more than fifty years ago.

The second problem that troubles the foundational weight attributed to Revelation arises from the reflection recently offered by Pope Emeritus, Benedict XVI, concerning sexual abuse in the Church, its causes and dealing (Benedict XVI 2019). It must be recognized that this Pope has had the great courage to address an issue that most theologians have preferred to ignore, and to lend his own analysis, which should give rise to an urgent and too postponed discussion. Among the most interesting points in these reflections, although secondary to the underlying topic, one refers to the efforts in the post-conciliar season to elaborate a moral theology based on Revelation. Pope Emeritus cites the studies of "Father Schüller" to affirm that morality cannot be systematically built on the basis of Scripture; or, in other words, that Revelation is not enough to provide a convincing ground to moral theology. Commenting on this text and that opinion with colleagues in the field of Catholic moral theology at my Antonianum University, they told me that this was something obvious for them, since several moral questions had arisen in recent decades, especially in the bioethical field, which had no reference in the Bible, and whose treatment had to resort to other sources for plausible arguments.

Now the big question is, if we accept that diagnosis and assume that Catholic moral theology cannot be based only on Revelation, how far can this perception go? Does it affect other theological treatises, or is it limited to moral theology, and possibly other practical theologies? Several answers come to mind before such a critical question. In a minimalist view, it could be said that the consequences are very limited, and that this opinion does not have to touch other theological treatises, which would be strongly rooted in Biblical Revelation. However, suspicion accompa- 
nies those who believe that Pope Benedict's criticism has more serious consequences for the whole theological field, and that many other treatises can become involved or somehow be suspicious, in the sense that Biblical Revelation would only provide a partial contribution for the updating efforts aimed to show the credibility of Christian faith and its contents. In fact, it is likely that the scope and reach of Biblical Revelation must be resized at this stage, in which the Biblical text continues to be an essential source of inspiration, but at the same time, other sources of human knowledge are required as a necessary complement. This is especially the case at the current time, where new criticism and an expanded scientific view impregnate the ambient cultural. It is relatively easy to enlarge the notion of revelation to include other natural sources as well, or history, the arts, and the sciences, but then there is a risk that if everything is 'revelation' then the strong and univocal meaning we attribute to that term, which basically relates to the sacred text, or which finds there a special, unique concentration, could be threatened

This is just a part that fully touches the core of FT and forces us to review some of its broadly shared assumptions. If Fundamental Theology must consider the relationship between Revelation and theological elaboration, then it cannot be indifferent to these developments, and the meaning and scope of Revelation must be rethought within a broader scheme in which other sources of knowledge come into play, perhaps in a different way. This is something we learn from contemporary hermeneutics, which has matured for several decades along this line, showing the enormous complexity that presides the relationships between ancient texts, history, cultural environment, and personal and community reception.

\subsection{Why recent Popes' teaching changes many things?}

The last indication introduces the following point, which can be associated with the magisterial pressures to render theology - and even more the Fundamental - the scope of the dialogue between faith and reason. I am not sure to what extent theologians have noticed the important change that such an orientation implies, and that Pope Benedict XVI strongly promoted, but that became probably the least appreciated or received 
idea from his rich magisterium, even among the most 'Ratzingerians'. It is one thing for theology to be a "theory of revelation", and quite another to become the meeting place between faith and reason. In the first case, theology is conceived as an effort to update the contents of canonical revelation, which sets the orientation and also determines the language, the keys and even the style of theological discourse, which in the limit becomes an intra-textual exercise close to biblical theology (Lindbeck 1984). In the second, theology takes seriously both its own tradition and the impulses from reason, not only its historical expressions, but, above all, contemporary ones, to show how faith is a reasonable option, and to fertilize, and if necessary correct, from that standpoint reason and its main expressions. The second model focuses more on dialogue and the ability to assume the stimuli and objections coming from culture, philosophy, and science.

The model proposed by Benedict XVI, to which he has insistently drawing attention, although with little success, receives an accolade with Pope Francis and his teachings. In that sense can be understood his invitation to a theology 'on the way out', or less self-referential and more capable of interacting with other human knowledge and insights, welcoming different sensitivities and stimuli. The Constitution Veritatis gaudium proposes a model, or even a new theological style quite different from what we were used to. That document insists on interdisciplinary practice and a format open to alternative expressions of reason and rational or scientific enquiry. The question is to what extent these stimuli affect the already established FT program. In my opinion their effect should be enormous, eliciting even a 'theological conversion'. In general, the impact could be deeper in FT epistemological part, or in the study of the conditions that preside the theological exercise and its method. Theology is seen as a process that conforms to the truth ideal and that assumes guidelines in its development aimed at keeping rigorous standards and the expected demands proper of every academic activity. All this, in addition, necessarily affects a program that tries to build the best possible relationships - not excluding tensions - between normative texts we receive from the Great Tradition, and the cultural contexts that determine the conditions that 
render plausible or respectable an academic discourse; i.e. subject to scrutiny and discussion by colleagues also from other areas. In any case, this dimension broadly attributed to FT is not overly developed either, since it should also include hermeneutic analyses on the value of religious experience, and questions on the structure and dynamics of believing, a field that knows an important development in the last number of years.

\subsection{In what sense are we to be concerned with the credibility of faith?}

A broad consensus has been reached regarding FT and its design: this treaty should comprise at least two major sections: the first studies Revelation, its transmission and reception, and the second deals with Christian faith and its credibility. Furthermore, an epistemological section could be added, something frequently neglected. While the first part has undergone an almost exhaustive development, the second has largely become, in most cases, the Cinderella, and only in recent years practitioners became aware of its importance and the need to pay more attention to issues arising around faith and the difficulties to believe. Indeed, the impression we get from reviewing FT manuals or the curricula describing FT courses is that the greatest effort is devoted to the study of Revelation, while the second part receives limited attention.

Another difficulty has been that it was also unclear what is the most appropriate treatment for that topic. For many authors, the important thing has been rather to show the anthropological conditions of possibility that allow the divine Revelation to be received and accepted, something that is normally solved by resorting to various models - either transcendental, ideal, or aesthetic - that support the human positive disposition towards divine messages. In this sense, credibility is reduced to showing the openness of humans to faith, their positive disposition. Indeed, in some cases, this second part was associated with the theological virtue of faith, which caused somehow FT overlapping with theological anthropology, a subdiscipline where this topic makes more sense.

In other cases, credibility has been associated with the historical credit deserving Christological references and, in some cases, it also was related to the most difficult point concerning what can legitimize the Church as 
an institution that mediates salvation. In both senses, although some interferences could arise with Christology and Ecclesiology, in my opinion, that effort is crucial and corresponds more to FT, that is, to its program aiming to offer arguments for the universal salvific meaning of Christ and the church. However, a broad impression is that we have often fallen short, and the Fundamental has not been able to offer good arguments or explore all the resources available to make its case, especially when it comes to defending the value of the Church as an institution, and not as an idealized or spiritual entity.

Several FT practitioners have claimed that the best treatment we can dispense to the credibility issue needs to resort to the witness of believers, in the sense that the most credible is the best example that Christian life can provide, and less the arguments or good reasons we can build (Pié I Ninot 2017). This position makes sense, and it needs to be accounted for, but several problems arise when it becomes the only resource to offer supporting Christian faith as a credible attitude. First, if living witness is the key to credibility, then we move to another field: practical theologies, such as pastoral and spirituality, where possibly FT has little to say. Second, a big problem in these years is that churches need to cope more and more with many anti-testimonies, outweighing positive or constructive witnesses; indeed, too many scandals shake faith at its roots and its practical plausibility. And third, apparently if we focus on living witness and do not do more, then all the great objections that Christian faith faces would be neglected. This problem is more pressing in advanced societies and in the unavoidable tensions with a scientific and critical mindset, increasingly widespread in our cultural settings. Indeed, most FT manuals and courses systematically ignore these aspects, that is, the treatment and responses that deserve hard problems such as secularization, cultures of unbelief, the pressing presence of other religions, historical errors with all their negative load, the current scandals, and the growing impact of science. All these points deserve a specific treatment to provide good argumentative resources, especially for those students who must exercise a ministry and will face these harsh questions in their praxis, or simply 
must educate young generations with their many questions and scarce religious interest.

A different but closely related question concerns the credibility not so much of the faith, but of theology as a theoretical undertaking that tries to offer the best explanations on religious beliefs, and in particular on the Christian faith. In recent years we are witnessing a disastrous divorce between the traditional proposals from theology and philosophy of religion, on the one hand, and the new scientific study of religion, on the other. Basically, it is about deciding who can offer a more accurate and useful knowledge about the human wide religious dimension and its held beliefs, its practices and expressions. At a personal level, many experiences are quite discouraging. For example, I attended last year the conference of the European Association for the Study of Religions (EASR), which took place in Tartu, Estonia in June 2019. Surprisingly some 600 scholars attended, but among them there were very few theologians. The same has happened to me in other international conferences devoted to the scientific study of religion, and where, systematically, theologians were absent. The ongoing divorce can seriously damage theology and its credibility, now under pressure from colleagues who apply other methods and approaches to better understand religious processes. We run the risk of displacing theology to a merely internal discourse, with little academic scope except the formation of future ecclesial staff. Nonetheless, theologians may feel in those cases and reading the extensive recent output in the field of the new scientific study of a déjà $v u$ in describing religion, and that frankly not much is learned from that heavy flow - indeed very wellfunded - and their contributions. Probably theology has much more to teach than to learn in these environments, but it would not hurt to look at them and try to connect our own knowledge and our vast experience with all this new development, if only to claim our own expertise, and to adopt languages, theoretical models and styles that can be useful for theological development on its own. 


\section{What Can We Do? Proposals to Renew the Fundamental Theology}

In the first place, I am convinced about the importance to take seriously the relevant Magisterium and the indications the last Popes have given with direct impact on this treaty. The most relevant is probably the invitation to engage more committedly in the dialogue between faith and reason. Theology as has been conceived by those Popes - and especially by Benedict XVI - needs to be built on that program. A theology on the way out - as Pope Francis insists- needs to connect and dialogue fruitfully with other knowledge that is contiguous or relevant for theological development. As a matter of fact, this point does not mean leaving aside the Revelation theology. In most cases, that point is already very mature and offers a well-developed treatment, after several focusing decades. However, other areas in FT need to be expanded, after being left somewhat behind due to the strong emphasis that that first part - revelation - has enjoyed.

In an attempt to offer a constructive reflection, it may be helpful to consider a recent collective book published under the iconic title What is Fundamental? (Aguirre et al. 2019). Although this book raises the question from a philosophy of science perspective, its various proposals can help us to address a similar issue in the theological field. Indeed, the question remains in these multiple interventions quite to the point: the 'fundamental' can be understood as the most elemental, that is, the particles and forces that form the blocks with which the universe is built. In this first sense, fundamental refers to the most basic or essential elements that constitute matter. A second sense points rather to the physical laws that govern the cosmos, constants and relationships, all of which contribute to its relative stability and development until reaching the state we know. However, other authors in the same book move to the epistemological or cognitive field, to identify the 'fundamental' rather in the subjective area, and associate it to consciousness, to the dynamics that allow knowing and understanding reality. 
What can we learn from this attempt to fix the fundamental from a scientific point of view? In my opinion, FT has also distinguished and should continue to distinguish these two dimensions: the fundamental refers both to the content of a revealed message and to the experience of lived faith, and both dimensions are inseparable, or can only be separated in a heuristic way, to be then harmoniously combined. In addition, it is also worth adding the problem where to place and how to conceive the Fundamental in theological work, which surely consists in developing a hermeneutic focusing on normative texts and the believing experience. That exercise requires good preparation and skill, something that cannot be taken for granted. If this program is followed, FT should pay more attention to everything that refers to religious experience, a field that has grown a lot in recent decades, including studies on the structure and processes of believing, with highly interesting developments. To this must be added, without a doubt, the advances in the new scientific study of religion, which has expanded with a considerable production during the last 20 years and nowadays compete with theology in trying to better understand religion. All of that invites us to make more place in FT for that dimension. I am not talking about the debate on the normativity of objective revelation for the subjective experience, and about that $e x-$ tra nos axiom that continues to keep full force. What is vital is to better understand and integrate within a fundamental perspective the believing subjectivity, its trials, and its way to access, understand and integrate the normative proposals that Christian tradition announces. Again, the pressing question is whether, together with the 'fundamentality' of revelation, we can also place the fundamental character of faith lived in all its complexity, always in dialogue with reason and science.

When redesigning the FT map in this new stage, theologians need to take into account, in addition to the indications from the Popes' Magisterium already quoted, the contexts in which this sub-discipline should be elaborated. The first is clearly internal to theology itself and to all its treatises. We must consider the role and contribution FT provides, to avoid falling into a simple section belonging to dogmatic or systematic theology, dealing with the study of revelation. The challenge is to 
become a treatise with its own personality and style, capable of being able to fill gaps that other theological areas cannot cover, especially what concerns the credibility of Christian faith and involves the dialogue with culture and the contexts where that faith is announced. Also, epistemological and methodological issues should draw FT's attention, something that certainly falls within what can be considered as 'fundamental'. The other, wider context is clearly that of society, culture and science, which condition religious experience broadly speaking, and Christian faith in particular, its reception and living. That condition motivates a steady exercise of inculturation, which should be guided by FT to assist other theological treaties.

After those general indications, several points require special attention now in order to reactivate FT as an updated program: first, an invitation to rethink the hermeneutic question and different theological styles within the epistemological section; second, a deeper study of believing, its dynamics, and its relationship with Christian faith; third, a better development of theology and faith in relation to natural and social sciences; fourth, a study able to address the objections to faith from a more practical point of view; and fifth, a defence of theology and its function. In what follows, this program is shortly introduced for a renewed and extended FT, something beyond what is usual in the handbooks devoted to this treaty in the first theological study level.

\subsection{Theology and its many styles}

Theology is - from its beginning - eminently plural, a point that has been quite neglected in its current approach. This is a de facto characteristic in our discipline, and it is certainly not something to be ashamed of, because it would distance us from scientific ideals, when we present our work as something rigorous and that requires various controls. Indeed, many sciences know a similar feature: a plurality of paradigms coexist often in competition, and other times as complementary or at least not exclusive. Many understand it as a wealth and a positive symptom, while others find it as a limitation, an obstacle on the way to the ideal pointing to reach a unique truth and complete theories. 
The suggested topic should be clearly raised within a section in FT that includes epistemological issues and containing the conditions of rigor and reliability required in theological research. That question includes methodological plurality, which must necessarily assume the addition of empirical methods and how to face the contextualization and transdisciplinary tasks to which the recent Magisterium invites us, and about which many specialists do not know how to proceed.

Surely theology is - in several senses - a plural discipline, where diverse styles, orientations and paradigms coexist, from its beginnings. What should concern theologians is whether such pluralism might lead to chaos or renders theology a creative exercise without controls or the possibility to verify its contents and proposals. Since many styles coexist, then we need - in the first place - to organize and classify that plural set, based on clear criteria. Among the classic attempts to address this issue in twentieth-century theology, Richard Niebuhr's well-known essay Christ and Culture (1951) appears in a prominent place. His popular five models tried to cover a spectrum that ranges from further contrasting faith with culture, until the models assuming greater assimilation between both extremes. After Niebuhr, several other attempts did follow suit, applying other criteria (Frei 1992; Bevans 1992). These proposals greatly facilitate the task of organizing the plurality of theological forms or styles. Secondly, the assumed pluralism involves a needed discernment, which must be given from time to time, to verify which model or models are more suited or respond better to what the respective culture demands. Such a mission involves the need to refine the instruments we apply to social and cultural analysis, and also invites to use empirical methods to discern the expressions that best contribute to transmitting faith and to build the Church.

In my own view, the task just described should be included in the hermeneutical dimension of FT, and therefore in the epistemological section conforming a "theology of theology", which should not be neglected when we try to lay down the foundations on which the theological reflection and analysis can be built and progress. This, obviously, requires a broader effort to include the presentation of plural theological models 
or types, their expressions, functions or mission, and also the critical vision revealing the inevitable limits affecting each partial expression. The hermeneutical question should be developed in terms that help to choose in a fitting way the most convenient model or scheme to interpret revelation and faith in each time and cultural context, bearing in mind that theology cannot avoid having to choose and decide each time as a healthy and needed exercise.

\subsection{Deepening the study of beliefs and religious cognition}

Many new studies try to better understand the less obvious aspects of religious mind (Jones 2016), which usually could appear as more intuitive or implicit, and the formation of beliefs, their resistance and their crises (Seitz and Angel 2014; Angel et al. 2017; Castillo 2015; Connors and Halligan 2015; Smith 2014). Two different programs emerge, and both also affect Christian faith and theological reflection, which has also been analysed from that perspective (De Cruz and Smedt 2014). Faith has been traditionally object of theological enquiry and the FT program. That point has been built, like almost all contemporary theology, on Revelation and the many narratives telling about experiences of believing and appeals to accept Christian proposals. Probably much more can be done, given the advances in cognitive psychology applied to the study of religion and the developments in the study of beliefs, their epistemic value, and their relationship with other mental dimensions, such as perception, emotions, and also with external factors, like culture and collective imaginaries.

FT may hold legitimate doubts about a program that involves many risks. It seems clear that the aforementioned studies might have some relevance when trying to better understand the processes of believing, but obviously, in this case, we are doing cognitive psychology, not theology, which normally drinks from other sources, follows other methods, or has other functions. This is surely an important point that should not be neglected and needs to be addressed. The quoted studies represent a body of knowledge and data that are clearly relevant to FT, but which have a quite different character as the usual materials on which theologians' research proceeds. The challenge is to render such data and information 'theologi- 
cal' or to practice a theological reading of plainly secular, often secularizing, and decidedly naturalistic discourses. I do not think that such a task must be that difficult: it requires rereading those investigations in a key proper to theological interests, or connecting them with our interest in spreading and plausibly expressing salvation in Christ and the meaning of Christian faith.

Very likely, Fundamental theologians can learn a lot from developments in cognitive sciences, for example, when distinguishing between more intuitive or immediate forms of cognition, and slower or more reflective forms. Such a distinction helps to better understand popular religiosity, or the more spontaneous 'natural' religiosity and the contrast with theology and its demands. Belief studies become very useful in thinking better about the processes that contribute to acquiring faith, the causes of their crises, or the difficulties in believing that we find in many people today. Furthermore, these studies clearly dignify the experience of faith and place it in a much higher level than it used to be in previous attempts to understand that cognitive attitude, whose epistemological quality is today beyond doubt. In any case, in addition to the apologetic meaning that this research suggests, other aspects arise concerning the necessary balance in the believing attitude and the need to understand both its positive functions and its most pathological expressions.

\subsection{Reviewing the relationship between faith, reason and science}

The relationship between faith and reason has almost always embodied some tension, often constructive, but it also could elicit crisis and become dialectic. Also in this case, the different styles or models formerly referred to find an application: some styles assume a greater theological commitment to standard forms of rationality, and others are proposed precisely in contrast to them, such as its dialectical negation or as an alternative to reason. After drawing such a map and the different expressions that it can bear within Christian theologies, it is convenient to assume in FT a positive, open, and dialogical commitment. That is not the only form that FT can take; indeed, a dialectical style or one that contrasts with standard reason is perfectly legitimate, but it is a necessary 
and convenient one for our sub-discipline; someone has to take up this challenge and develop a more dialogical program. It would be a great failure if nobody, no longer, would be able to address the challenge to relating faith to reason.

The vocation to dialogue that should characterize FT leads it directly to meet the dominant forms that rationality embodies, as present in the western cultural environment, and therefore to examine its most significant or far-reaching expressions, especially in the academic field, when describing its most widespread or high-impact models. Also in this case, pluralism is the norm, and surely a previous task requires a systematic list gathering these expressions and their representatives, for example, to what extent reason assumes a more pragmatic, consensual, utilitarian, empirical or formal format. Clearly, in this panorama a special place is taken by science, and philosophy of science assumes a relevant position as well.

Theology must consider its place in a culture strongly impregnated by the scientific mentality, which forces it to adapt or at least express itself in terms that can be understood within that mentality. For many, FT should be responsible for explicitly proposing the rules of that game, the forms of interaction, the demands and the limits that must be observed. It should offer an overview, capable of updating our fellow theologians from various sub-disciplines, on the current endeavour and open possibilities that science offers. Then, it is up to various theological treatises to develop their possible interactions, as in the case of theological anthropology or the creation treatise. Epistemological questions are extremely important in this interaction, and confronting the natural sciences helps to raise much better the identity proper of theological knowledge, as well as the possible convergences and theology specificity. All this is essential if we want to offer a more convincing discourse on faith and its credibility, and we want to go beyond the idealistic forms that have dominated much of contemporary theology, distancing it from reality and our cultures. 


\subsection{A practical sense of the credibility issue}

If theology wants to address the problem concerning the credibility of Christian faith, as a central task in FT, then we need to consider it in an eminently practical way, that is, starting from the question: what renders such faith less credible, or which are the obstacles that prevent people from believing. It is all very well positing theoretically the question about the anthropological conditions that favour faith credibility. This is an exercise that has been already practiced and has given more than satisfactory results. But now it is not that point. The question is not theoretical, but practical, and it would be convenient to address it from a broad survey or field work, that is, from a more ethnographic or cultural approach to the difficulties to believe that many people encounters in our time.

To start with, theologians hold several ideas and experiences in this regard, since we have all faced situations of disinterest or indifference and even open hostility towards faith, and - even more - towards Christian Churches. Now, it is about practicing a more systematic exercise in diagnosing these problems or objections to Christian faith, to address them in the most appropriate way. For example, many may claim that past and recent scandals that have sprinkled the Church discourage them from approaching faith. Our duty in that case, for FT, is to analyse these scandals, their consequences, and to look for strategies to address that issue or to help clarify and correct the perceived negativity. A similar approach should be applied in other cases, such as the indifference or disinterest many feel towards religious questions in general, or towards the Christian proposal in particular. It is urgent to analyse the causes and factors that influence this attitude with all the means at our disposal, also resorting to auxiliary sciences, to design the best strategies to deal with such a disconcerting disinterest and superficiality.

The suspicion could arise that the approaches described delimit towards practical theologies, which would be more fitting to analyse and address those problems, and to provide the best treatment between the theoretical study and the practical intervention. Probably in this case an overlap happens between one sub-discipline and another. However, the 
credibility of Christian faith should be raised and developed firstly and more accurately in FT, giving rise to a multidisciplinary exercise capable of providing good analysis and arguments helping to address the perceived problems, and serving as a ground for more practical theologies. In theology, each area has to do its specialized work, but it is also true that more coordinated work is required today, and perhaps that coordination is also a task proper to FT. We talk about 'systems engineering' to refer to a program that tries to cover in a multidisciplinary way the various aspects involved, for instance, in the design of an electrical network. It is worth asking whether FT might assume a similar format, something like a 'systems theology' to integrate the different components and factors that intervene in faith, its perception and living, its credibility and its dissemination. It is a rather ambitious plan, and one that invites a process that goes from 'systematic theology', a title that in many cases replaces 'dogmatics', to 'systems theology' or an approach that raises theological reflection as a an effort to bring together and integrate elements from different disciplines to address the serious challenges facing faith today.

In the appointed sense, the Fundamental would also have to ask questions about the legitimacy and desirability of the Church as an institution present and active in advanced societies, where it suffers constant distrust or simply disinterest, becoming in many cases redundant. Although the issue may be framed within a fundamental ecclesiology, it is again a rather practical question, trying to find solutions to the serious problems and crisis now threatening its existence. This issue is much more than just a pastoral question - which certainly it is too - and requires the development of arguments to justify that institution and its social function, a task that can be assisted by several social sciences, which could help to better understand the nature of huge religious institutions and their many uses, performances and possibilities in already post-secular societies.

\subsection{Theology as an open question}

FT has today to cope with a deep issue that threatens all theology as a meaningful and useful activity inside the Church and in the broad academic milieu. The last years have known strong tendencies questioning 
the need and even convenience of such academic effort. Theology has been discredited in many places as a waste of time, a gratuitous speculative exercise, or even a distraction regarding the urgent duties Christians have in mind. Probably recent theological development itself is to blame for that negative perception. A discourse heavily disconnected from real life and problems, too self-referential, and alien to contemporary forms of reason and science, might appear to many - believers and not - as lacking worth and interest, as something internal to a reduced group of specialists, without any practical effect.

It is an urgent task for TF to address that issue, and to justify why theology is necessary and important, both for Christian Churches and for secular societies, which cannot ignore the ultimate questions and the deeper issues that often invite to transcend the narrow framework of our material world. This is something many theologians ignore, or we are used to see our work as meaningful and good for all, but in reality, inside and outside the Church, many people do not appreciate at all this effort, even among the clergy, often disappointed after a theological formation that does not provide enough tools to cope with the many questions and challenges arising in their pastoral praxis. TF needs to pose those questions: what is theology good for? What can it provide that other disciplines cannot? What difference can it make having or lacking a good theology for believers and unbelievers? Answering those issues would render a great service to everybody, and still more to all the other theological branches.

\section{Some Conclusions}

Probably the program just suggested can raise the impression of proposing a project that is too broad and ambitious, something that covers too much areas and must solve too many problems. Italians use the word tuttologo to refer to someone who deals with many issues but does not delve into any deeply enough. FT was rather used to work within its own niche of specialization: the theology of revelation and faith answering to the revealed Word. The field was well defined, and the treaty has been developed in a practically exhaustive way; in fact, it is difficult to add some- 
thing new to what has already been produced in many high-level manuals and texts.

Now it is about something else, if we assume the program of a 'theology on the way out' and capable to dialogue with other disciplines and addressing the challenges and questions of our time. Rather, it needs to become a 'border sub-discipline', able to diagnose the serious problems and crises that faith is experiencing, and to give orientations and the most convenient responses. This program does not render useless the effort already made in the study of revelation, but rather expands it, recovering the best of the apologetic tradition, and paying attention to the question of credibility in a more concrete way and able to assume and answer the big questions concerning faith. It is time to take these problems seriously and to render FT the field in which we work to address them and to give useful guidelines for the entire Christian community.

\section{References}

Aguirre, Anthony, Brendan Foster, Zeeya Merali (Eds.). 2019. What is Fundamental? Cham, Switzerland: Springer.

Angel, Hans-Ferdinand. Ll. Oviedo, R.F. Paloutzian, A, Runehov, R.J. Seitz (Eds.). 2017. Processes of Believing: The Acquisition, Maintenance, and Change in Creditions. Dordrecht: Springer.

Barton, John. 2019. A History of the Bible: The Book and Its Faiths. London: Allen Lane.

Benedict XVI, 2019: https://www.catholicnewsagency.com/news/full-text-ofbenedict-xvi-the-church-and-the-scandal-of-sexual-abuse-59639.

Bevans, Stephen B. 1992. Models of Contextual Theology. Maryknoll-New York: Orbis.

Castillo, Ramon D., H. Kloos, M. J. Richardson, \& T. Waltzer. 2015. Beliefs as Self-Sustaining Networks: Drawing Parallels between Networks of Ecosystems and Adults' Predictions. Frontiers in Psychology 6, 1723. doi: 10.3389/ fpsyg.2015.01723.

Connors, Michael H. and Peter W. Halligan. 2015. "A cognitive account of belief: a tentative roadmap". Frontiers in Psychology 5, Article 1588. doi: 10.3389/fpsyg.2014.01588. 
De Cruz, Helen and Johan de Smedt. 2014. A Natural History of Natural Theology: The Cognitive Science of Theology and Philosophy of Religion. Cambridge, Ma: MIT Press.

Frei, Hans W. 1992. Types of Christian Theology. Yale: Yale University Press.

Jones, James. 2016. Can Science Explain Religion? The Cognitive Science Debate. Oxford: Oxford University Press.

Lindbeck, George A. 1984. The Nature of Doctrine: Religion and Theology in a Postliberal Age. Louisville, MO, London: Westminster John Knox.

Niebuhr, Richard. 1951. Christ and Culture. New York: Harper \& Row.

Pié i Ninot, Salvador. 2017. Teología Fundamental. Madrid: BAC.

Seitz, Ruediger J. \& Hans-Ferdinand Angel. 2014. "Psychology of religion and spirituality: Meaning-making and processes of believing”. Religion, Brain \& Behavior 5 (2): 139-147.

Smith, Aaron C. T. Thinking about Religion: Extending the Cognitive Sciences of Religion. 2014. Basingstoke, UK, New York: Palgrave MacMillan. 
